\title{
About Testing Students On The Discipline "Draft Geometry"
}

\author{
Tohir Azimov , Tashkent State Technical University Republic of Uzbekistan \\ Shakhnoza Akhmedova , Tashkent State Technical University Republic of Uzbekistan
}

\begin{abstract}
The article examines descriptive geometry as one of the fundamental academic disciplines that develop visual thinking, as well as the intuition of a future specialist, which is necessary for any creative activity, especially engineering and scientific ones. With the increase of the scientific information volume and emergence of the new disciplines in the curricula of higher technical educational institutions, the number of academic hours connected with the study of descriptive geometry decreases, the improvement of the teaching theory and methods of descriptive geometry on the basis of the new information technologies that activate the educational activity of students and develop their creative abilities. In these conditions, it is of great importance to determine which of the new teaching methods greatly affect teaching descriptive geometry and their further introduction into the educational process. Therefore it is necessary to apply innovative and scientifically grounded methods of current and final monitoring of students' knowledge. Lots of experts in the field of pedagogical qualimetry have distinguished the non-productive, non-objective, little diagnostic approaches to assessing the effectiveness of pedagogical activity that brakes the education system development. The problem of optimizing the content of the discipline taking into account the modern requirements is considered in the article.
\end{abstract}

Keywords: Educational process testing system, entrance tests, scientifically based, effective way of current control, testing in computer form, final academic performance, standardized tests, comparison of academic performance, new information technology, automation of results processing, use automated check.

Received: 08.12.2020 $\quad$ Accepted: 12.01.2021 $\quad$ Published: 02.02.2021

\section{INTRODUCTION}

Testing is one of the most scientifically grounded and effective methods of knowledge control; this method has a number of advantages over traditional oral and written exams, the disadvantages of which are high organizational complexity, high labor intensity, limited testing time, and the presence of subjective and psychological factors.

It is necessary to take a comprehensive approach to the implementation of the testing system in the educational process. If the adjustment of intermediate results is carried out systematically, then the more likely to achieve the set result. For the same purposes, input tests should be used more widely. They help the teacher to navigate in the level of preparedness of students for the beginning of the study of the discipline, because at the university, as a rule, teachers are narrowly specialized in specific disciplines and often work with students for only one semester. Entrance tests in descriptive geometry should be focused on identifying students' abilities for spatial reasoning. If the results of the entrance test are unsatisfactory, then more attention should be paid to the introductory lecture and the topic of projection, since without understanding the basics it is impossible to proceed to the study of the following sections.

To increase the efficiency of the educational process at the university, it is also necessary to develop tests used in current control - formative and diagnostic ones, designed to form the teacher's ideas about the gaps in the preparation of the subjects and their reasons, since the teacher's main work should be aimed at the formation of knowledge and skills.

Testing by topic allows you to determine how successfully each student and the whole group copes with the study of the material, to adjust the educational process, paying attention to the most difficult topics. Also, the teacher has the opportunity to individualize the learning trajectories of each student by issuing different tasks, depending on the results obtained.

A very important part of the organization of students' work with the test is the discussion of the test results, which, depending on its goals, can be either an individual conversation between the teacher and each student, or an analysis of the errors identified through testing and the establishment of the reasons for their 
occurrence, in which all students of the group participate. Most often, we go along the second path, because, as a rule, after completing the test, the so-called "typical" mistakes are discovered, made by a large number of students, which require public discussion and analysis.

Also, educational testing in computer form is very effective, when, after incorrectly completing the task, the student is presented with either a fragment of an electronic textbook on this topic, or a solution to a similar problem. After studying this material, the student is again asked to solve the problem ', which caused him difficulties.

Most often, the effectiveness of teachers' work is assessed by the final progress of students. At the same time, the indicators of progress (final tests, oral examinations, etc.) are different for each teacher. Therefore, to assess the effectiveness of their work, it is necessary to use tests as a single measure of the level of mastering the material for all students studying this discipline. Standardized tests provide material for comparing the performance of both students of different specialties of the same university, and students of the same specialty in different universities.

The main purpose of the final test is to provide an objective assessment of learning outcomes upon completion of the course. Depending on the achievement of this goal, conclusions can be drawn about the need for additional training, about the effectiveness of the work of a teacher or a group of teachers (department), about the effectiveness of various training programs.

However, like all science-based technologies, testing requires serious preparation on the part of those who intend to engage in the creation and use of educational tests. First of all, it is necessary to deeply master the strict rules and mathematical apparatus used in the field of pedagogical measurements. Incorrectly designed, not approved tests can only give erroneous results, so using them will become a step backward, not forward.

A bad test that does not meet certain quality criteria in one way or another can serve as a source of a distorted impression of students' knowledge. Moreover, it is impossible to correct this impression in the testing process, unless, of course, the testing process is massive, and not organized in an adaptive mode. This leads to the need for scientific substantiation of the quality of test materials and mathematical statistical processing of test results. The issues of scientific rationale involve three complementary areas of work. The first is connected with the justification of the selection of the content of the test, the second - with bringing the form of tasks to the level of the requirements of test technology, and the third is aimed at identifying the system-forming properties of the task based on the analysis of the results of processing empirical test data.

When creating a test, first of all, it is important to select the content, which can be defined as the optimal display of the content of an academic discipline in the system of test tasks. The requirement of optimality implies the use of a specific selection methodology, including the questions of goal setting, planning and assessing the quality of the test content.

When forming a bank of test tasks, one should take into account the requirements of testology for the formulation of tasks and the choice of destructors, these issues are discussed in detail in the works of many foreign and domestic teachers. The feature of descriptive geometry is. that students must learn to solve graphical problems on drawings, for example, positional and metric, therefore more than half of the test tasks we offer require the execution of constructions to get an answer.

The process of scientifically substantiating test quality is broken down into 3 stages: the stage of collecting empirical test results is the first, initial step. The second stage is the processing of empirical data and the third is the interpretation of the processing results in order to bring the test to the level of compliance with certain quality criteria. These criteria include objectivity, reliability and validity.

The use of new information technologies makes it possible to maximize all the advantages of tests, as well as to make knowledge control more efficient and cheaper. We have proposed the forms of testing depending on its goals and the technical equipment of the department, we have considered the issues of creating software for conducting the testing procedure in these forms:

- blank with manual verification and automated processing of results;

- blank with automated check of answer forms and automatic processing of results;

- computer.

The first form is the least preferred. it is used if the teacher does not have access to a high-speed scanner and a computer with a system for recognizing and processing test forms. In this case, the teacher either checks the forms and assigns marks manually, then the possibilities for scaling and improving the test are significantly narrowed, or enters the answers of the examinees and the keys to the answer options into a specially developed program. which gives marks and allows you to analyze the characteristics of tasks and the test as a whole. 
To implement knowledge control in the second form, we have created an "Automated complex of knowledge control based on blank testing", which allows you to: automate registration of participants (if necessary); scan and recognize forms; processing of results with a given level of reliability; print summary statements; To carry out statistical analysis: Currently, research is being actively carried out on the automation of document flow in universities, the development of databases in which the student's progress will be monitored from the moment of his admission to the end of the university. Therefore, both computerized and blank testing systems should have the ability to transfer results to an external database, and not just to a statement.

Working with the test, depending on the purpose of its use, can be organized in different ways. For example, if a test is used to control the assimilation of a topic, then after a preliminary acquaintance with the rules of work, students are invited to complete it on forms. In this case, the use of an automated check seems inappropriate, due to the complexity of its organization for small groups and. as a result, an increase in the time spent on processing blinks. The works are checked by the teacher or by the students themselves. We consider the second method to be very useful. For example, if time permits, we invite students to exchange their work in pairs and evaluate the correctness of their implementation using a standard. This not only diversifies the activities of students in the classroom, but also allows them to be involved in semi-professional activities, where each student acts as a teacher.

But the most promising is the use of test technologies in a computer form. Automated training systems are widely used in pedagogical practice, the main advantages of which are: the ability to use the advantages of individual training; intensification of the educational process; the possibility of individual adaptation of the training course to the needs of trainees or learning conditions, the possibility of using and replicating best practices; increasing the availability of education; teaching skills of independent work; unloading the teacher from a number of routine, repetitive actions (lecturing, checking tests, etc.): an opportunity used in the framework of distance learning, retraining and advanced training. An effective way of organizing the management of the educational process is an adaptive approach. The system adjusts to the learner, setting the sequence and intensity of learning materials based on the results achieved.

The testing subsystem of the complex we are developing consists of three blocks: the first - questions with a choice of the correct answer from several proposed options; the second - questions with a freely constructed answer, which is a number or a word; and the last - the most difficult - tasks requiring constructions, the answer is the projection of a line (straight, curve, broken line) or projection of a point basis.

Since the subject "Descriptive Geometry" has its own specifics, which is that the main skills that students must acquire are graphic, it is undesirable to transfer the solution of problems from paper to the monitor screen. In this way. students, passing the test, perform graphic constructions on paper. They are given tests, some of the tasks in which do not require the execution of constructions (blocks I and 2). and cleanness are full-fledged trophic tasks (third block). In the event that testing is carried out in a computer form, the tasks of the third block are issued for solution on paper, the answer is entered in a computer program, the tasks of the first two blocks are presented on the monitor screen.

On the other hand, we are implementing the solution of graph-geometric problems within the framework of computer testing, which will help reduce the cost of printing test materials, but will make the control of knowledge in this discipline less adequate, since the result is influenced by the skill of owning computers and specialized software. The negative impact of this factor can be reduced by more active use of information technology during the semester. If the current control of knowledge is carried out systematically using computer testing, then the trainees will not have problems using the software in the final exam.

The proposed method of knowledge control has been implemented at the State Technical University. Based on the analysis of the results obtained, it can be concluded that the main functions of testing, such as diagnostic, teaching and developmental, educational and mounting, as well as predictive, are successfully implemented when using this system in the pedagogical process when teaching the discipline "Descriptive geometry" and engineering geometry " ...

\section{References}

1. Azimov TD, Sabirova D. U collection of tests on descriptive geometry on the topic "Point" -T. Tashkent State Technical University, 2007- 42 p

2. Sabirova DU, Yakubova MM A set of tests on the subject of linear geometry on the topic "Straight line". TSTU, 2006-42 p 
3. Azimov TD, Mirzaraimova VT Collection of tests for the course "Engineering Graphics" 1-part. Tashkent State Technical University 2007-82St

3. Fayziyev Shokhrud Farmonovich Medical law and features of legal relations arising in the provision of medical services. International journal of pharmaceutical research Volume 11, Issue 3, July - Sept, 2019 P. 1197-1200 doi:10.31838/ijpr/2019.11.03.088 http://www.ijpronline.com/ViewArticleDetail.aspx?ID=11016

4. Bryanskaya Elena, Fayziev Shokhrud, Altunina Anna, Matiukha Alena Topical Issues of an Expert Report in the Process of Proving in a Criminal Examination. International Journal of Engineering and Advanced Technology (IJEAT) ISSN: 2249 - 8958, Volume-9 Issue-1, October 2019 5345-5349 DOI: 10.35940/ijeat.A2946.109119 content/uploads/papers/v9i1/A2946109119.pdf

5. Fayziev Shokhrud (2019) Legal Aspects of Transplantology in the Republic of Uzbekistan. Systematic Reviews in Pharmacy, ISSN: 0976-2779, Vol: 10, Issue: 2, Page: 44-47 doi:10.5530/srp.2019.2.08 http://www.sysrevpharm.org//fulltext/196-1575419211.pdf?1586863081

6. Tulaganova, G. Some issues of observance of international legal norms of fight against legalization of criminal incomes in the Republic of Uzbekistan Journal of Advanced Research in Dynamical and Control Systems 12(2 Special Issue), c. 143-155

7. Bazarova D. Some problems of counteracting crimes related to laundering of illegal proceeds in Uzbekistan Journal of Advanced Research in Dynamical and Control Systems. Volume 11, Issue 7, 2019, Pages 873-885 